\title{
Princípios para o Design de Jogos Digitais com base em Erro Humano
}

\author{
Game Design Principles based on Human Error
}

Guilherme Zaffari, André Luiz Battaiola

erro humano, design de jogos, desafio, diversão análise semântica, metodologia científica, discurso científico
Este artigo apresenta o resultado da pesquisa referente à incorporação, por meio de princípios, do Erro Humano ao design de jogos digitais. De uma forma geral, questões sobre Erro Humano são consideradas no desenvolvimento de interfaces em jogos digitais, porém, quando relacionadas ao design do jogo, são necessárias adaptações a elas, uma vez que o desafio é um fator importante para se proporcionar diversão e, sob a ótica do Erro Humano, o desafio pode ser considerado um erro. A pesquisa utilizou as classificações de Erro Humano, a triangulação de dados coletados via inspeção preventiva de erro e a teoria do fluxo expandida para possibilitar a formulação de um conjunto de princípios com o objetivo de compatibilizar o design de desafios lúdicos com os princípios do Erro Humano. A partir do resultado, concluiu-se que a aplicação do Erro Humano no design dos jogos tem um efeito positivo para o jogador, permitindo que ele interaja somente com erros associados à estética do jogo.

human error, game design, challenge, fun semantic analysis, scientific methodology, scientific discourse
This paper displays the result of the authors' research regarding to the incorporation of Human Error, through design principles, to video game design. In a general way, designers must consider Human Error factors throughout video game interface development; however, when related to its core design, adaptations are in need, since challenge is an important factor for fun and under the perspective of Human Error, challenge can be considered as a flaw in the system. The research utilized Human Error classifications, data triangulation via predictive human error analysis, and the expanded flow theory to allow the design of a set of principles in order to match the design of playful challenges with the principles of Human Error. From the results, it was possible to conclude that the application of Human Error in game design has a positive effect on player experience, allowing it to interact only with errors associated with the intended aesthetics of the game.

\section{Introdução}

A ideia inicial para essa pesquisa surgiu ao se considerar questões de Erro Humano - uma interação entre usuário e sistema em que o resultado não sai como esperado (Dekker, 2000) - em jogos de computador. O que se trabalha na interação humano-computador (IHC), em relação ao erro, são formas de se prevenir situações que tenham consequências indesejáveis para os usuários, e isso se aplica, 
em especial, ao design de interfaces (Woods et al., 1994). Ao se aplicar o conceito de Erro ao design de jogos digitais, se observou que os jogadores também cometem erros com frequência, o que resulta em uma condição de jogo expressa pela mensagem 'Fim de Jogo'.

Considerando essa comparação entre o erro em IHC e o erro em jogos digitais, pensou-se em aplicar os princípios de prevenção de Erro Humano ao design de jogos, contudo essas instruções sugerem ao designer que padronize ou limite a interação do usuário com o sistema, com a intenção de diminuir o risco de acidentes (Reason, 1990). Essa abordagem é incompatível com o design de jogos digitais, pois o designer projeta, deliberadamente, situações de risco no sistema a fim de criar tensão com o intuito de divertir (Fullerton, 2014). Como, então, aplicar esses princípios de Erro Humano ao design de jogos?

$\mathrm{O}$ artigo procura primeiramente descrever classificações e princípios de Erro Humano com objetivo de esclarecer quais questões teóricas foram relevantes para a pesquisa. Em seguida, é apresentado o processo de inspeção preventiva de erro, a triangulação dos dados coletados e a formulação do conjunto de princípios. O artigo se encerra com as considerações finais e as conclusões a respeito dos resultados das inspeções, o impacto do Erro Humano na experiência do jogo, bem como uma descrição das expectativas em relação aos princípios quando aplicados a um contexto de design de jogos digitais.

\section{Sobre Erro Humano}

1 Tradução livre feita pelo autor de: "Most people accept the term 'human error' as one category of potential causes for unsatisfactory activities or outcomes."
"Erro humano" é a expressão que se atribui a variabilidade da performance humana na interação com um artefato. Em outras palavras, uma situação onde a pessoa tenta interagir com um objeto (como uma máquina) e algo sai errado. O resultado dessa interação é algo inesperado e indesejável para o indivíduo. Woods et al. (1994) afirmam também que "a maior parte das pessoas aceita o termo 'Erro Humano' como uma categoria de causas potenciais de resultados ou ações insatisfatórias."

$\mathrm{Na}$ intenção de tratar de forma científica, consistente e confiável o estudo dos acidentes causados pela variabilidade da performance humana, pesquisadores têm estudado esse fenômeno visando identificar suas causas e os fatores envolvidos nas suas ocorrências. Dessa forma, neste item, são apresentadas definições, princípios, e classificação de tipos de Erro Humano. O objetivo dessa coleta de teorias visa a fundamentação e a aquisição de conhecimento sobre o assunto. Algumas das perguntas que se procura responder são:

- Quais são as classificações existentes criadas pelos pesquisadores dessa área?

- Quais são as regras que existem para se desenvolver sistemas seguros?

Ao responder essas perguntas, é possível identificar mais facilmente o Erro Humano durante a etapa de inspeção dos jogos 
digitais, tornando possível o discernimento entre uma ação que resultou em erro do jogador e um problema de programação no sistema de interação. Além disso, conhecer o que as recomendações de design com base no Erro Humano estabelecem como "boa conduta" permite que elas sejam usadas na criação dos princípios que são o objetivo desta pesquisa.

Importante ressaltar que a intenção deste item não foi de traçar o panorama mais completo de classificações e princípios de Erro Humano possível, mas sim buscar familiaridade com o assunto para o melhor uso desse conhecimento nas etapas seguintes do projeto.

\subsection{Classificações de Erro Humano}

Existem várias classificações de diversos autores. Neste item, se faz um levantamento dos tipos considerados por Reason (1990), Baber \& Stanton (1996,1997), e Kirwan (1998). O primeiro autor faz sua classificação com base no modelo SRK de Rasmussen (1983), enquanto os outros usam como base a análise da tarefa conduzida em estudos prévios.

\subsubsection{Classificações de Reason}

Reason (1990) utiliza o modelo SRK - Skill, Rules and Knowledge como base para criar suas classificações. Segundo Rasmussen (1989), autor do modelo, existe a possibilidade de utilizá-lo para compreender outras questões relacionadas com o comportamento das pessoas, uma delas sendo o Erro Humano. O quadro 1 contém as classes que Reason (1990) formulou.

A classificação de erros estudados por Reason (1990) demonstram interesse em categorizar as falhas que o usuário pode cometer com base em seu comportamento, dando a entender que o importante de se observar é o indivíduo e como ele se comporta perante o sistema, com a intenção, assim, de diagnosticar no usuário a causa do acidente. 
Quadro 1 Classificação de Erros de Reason (1990)

\begin{tabular}{|c|c|c|}
\hline Classe & Descrição & Exemplo \\
\hline Erros no nível das perícias & $\begin{array}{l}\text { Ocorrem quando o usuário sofre } \\
\text { algum tipo de interferência na } \\
\text { sua performance devido a fatores } \\
\text { intrínsecos,como distração, } \\
\text { desorientação e esquecimento. }\end{array}$ & $\begin{array}{l}\text { Colocar a marcha errada na } \\
\text { embreagem do carro, indo da } 1^{\underline{a}} \\
\text { para a } 4^{\underline{a}} \text {; pisar no acelerador ao invés } \\
\text { da embreagem. }\end{array}$ \\
\hline Erros no nível das regras & $\begin{array}{l}\text { Surgem devido a uma associação } \\
\text { incompatível entre a abordagem } \\
\text { padrão, adotada pelousuário e o tipo } \\
\text { de problema a ser resolvido. }\end{array}$ & $\begin{array}{l}\text { Usar a } 2 \text { a marcha para mover um carro } \\
\text { do lugar; no xadrez, mover um peão da } \\
\text { mesma forma que se move um bispo. }\end{array}$ \\
\hline Erros no nível do conhecimento & $\begin{array}{l}\text { Manifestam-se na falta de um } \\
\text { conhecimento específico para resolver } \\
\text { um problema, ou noconhecimento } \\
\text { incompletopara desempenhar uma } \\
\text { funçã, ou ainda no conhecimento } \\
\text { incorreto sobre um conceito. }\end{array}$ & $\begin{array}{l}\text { Ativar um forno micro-ondas sem } \\
\text { conhecer a função de seus controles. }\end{array}$ \\
\hline
\end{tabular}

\subsubsection{Classificações de Baber \& Stanton}

Por outro lado, Baber \& Stanton (1996) fazem uma relação de tipos de Erro Humano que vêm diretamente da análise da tarefa. Para os autores, essa atividade é determinante para categorizar tipos de erros, além de ser importante para a análise do Erro Humano. Em seu trabalho, eles definem seis classificações expostas no quadro 2.

Quadro 2 Classificação 2 de Baber \& Stanton (1996)

\begin{tabular}{ll}
\hline Tipo de Erro & Exemplos \\
\hline Erro de ação & $\begin{array}{l}\text { Operação muito longa ou muito curta; Operação no tempo errado; } \\
\text { Operação na direção errada; Operação em excesso ou insuficiente; Desalinhamento. }\end{array}$ \\
\hline $\begin{array}{l}\text { Erros de comunicação da } \\
\text { informação }\end{array}$ & $\begin{array}{l}\text { Informação não comunicada; Informação comunicada incorreta; Informação } \\
\text { comunicada incompleta. }\end{array}$ \\
\hline Erros de consulta da informação & Informação não obtida; Informação errada obtida; Consulta da informação incompleta. \\
\hline Erros de Leitura & $\begin{array}{l}\text { Leitura omitida; Leitura incompleta; Leitura correta no objeto errado; Leitura errada } \\
\text { no objeto certo; Leitura fora de hora. }\end{array}$ \\
\hline Erros de planejamento & $\begin{array}{l}\text { Condições prévias do plano ignoradas; Plano incorreto executado; Plano } \\
\text { correto executado, porém, de forma inapropriada; Plano correto executado, } \\
\text { mas de forma adiantada ou atrasada; Plano correto executado, mas em ordem errada. }\end{array}$ \\
\hline Erros de seleção & Seleção omitida; Seleção errada. \\
\hline
\end{tabular}

Baber \& Stanton (1996) procuram focar sua classificação de erros na análise da tarefa, ou seja, toda vez que alguma das violações acontece durante a observação da atividade, pode ser apontado o tipo do erro. Observa-se que da classificação 1 para a 2 se acrescenta a classe de erros de planejamento, enquanto se retira a de erros de controle. 


\subsubsection{Classificações de Kirwan}

Após o trabalho de Baber \& Stanton (1996), uma nova tabela de tipos de erros é desenvolvida em estudo por Kirwan (1998). Segundo ele, a nova categorização, representada no quadro 3, é a mais aceita pela maioria dos estudiosos.

Quadro 3 Classificação de Kirwan (1998)

\begin{tabular}{ll}
\hline Classe & Descrição \\
\hline Erro por Omissão & Omite a tarefa por inteiro; Omite um passo na tarefa \\
\hline Erro de Tempo & $\begin{array}{l}\text { Ação tardia; Ação precoce; Tempo acidental com outro evento; Ação muito curta; } \\
\text { Ação muito longa. }\end{array}$ \\
\hline Erro de Sequência & $\begin{array}{l}\text { Ação em sequência errada; Ação repetida; Erro latente que previne execução (ex.: } \\
\text { uma engrenagem defeituosa impede que um portão se feche). }\end{array}$ \\
\hline Erro de Qualidade & $\begin{array}{l}\text { Ação em excesso; Ação insuficiente; Ação na direção errada; Erro de alinhamento } \\
\text { (ex.: quando as rodas de um carro estão desalinhadas); Erro de qualidade ou } \\
\text { de precisão. }\end{array}$ \\
\hline Erro de Seleção & $\begin{array}{l}\text { Ação certa em objeto errado; Ação errada em objeto certo; Ação errada em objeto } \\
\text { errado; Erro de substituição (ex.: quando se substitui o pneu furado de um carro } \\
\text { por outro pneu furado). }\end{array}$ \\
\hline Erro de Transmissão de Informação & Informação não comunicada; Informação errada comunicada. \\
\hline
\end{tabular}

Uma questão observada e importante de apontar é a semelhança da classificação de erros que Baber \& Stanton (1996) e Kirwan (1998) usam e os pontos onde essas classes se sobrepõem. Para a pesquisa conduzida, foi possível combinar as classificações desses autores em uma só, subtraindo o que é redundante e mantendo o que é diferente.

\subsubsection{Classificações Reunidas}

Os erros de ação de Baber \& Stanton (1996), por exemplo, podem ser separados em erros de tempo e qualidade, como faz Kirwan (1998). Os erros de comunicação e consulta da informação de Baber e Stanton (1996) podem ser somados ao erro de transmissão da informação de Kirwan (1998). Ambos autores utilizam a mesma definição para erros de seleção, entretanto Kirwan (1998) detalha essa classificação com mais exemplos. Assim, para identificar os erros cometidos pelo jogador durante as sessões observadas nos jogos na fase de coleta de dados, foi utilizado o quadro 4 que mostra as classificações de Reason (1990), e combina as classes de Baber \& Stanton (1996) com as de Kirwan (1998), como sugerido. A forma como essa reunião de tipos de erros foi usada na pesquisa é descrita com detalhes na próxima seção. 
Quadro 4 Reunião das classificações de tipo de erro com base em Reason (1990), ao lado da combinação das classes de Baber \& Stanton (1994) com Kirwan (1996).

\begin{tabular}{ll}
\hline Reason (1990) & Baber \& Stanton (1996) e Kirwan (1998) \\
\hline Erros no nível das Perícias & Erros no nível das Perícias \\
Erros no nível das Regras & Erros no nível das Regras \\
Erros no nível do Conhecimento & Erro de Planejamento \\
& Erro de Qualidade da Ação (Kirwan extrai dos erros de ação de Baber \\
& \& Stanton) \\
& Erro de Seleção \\
& Erro de Sequência \\
& Erro de Tempo (Kirwan extrai dos erros de ação de Baber \& Stanton) \\
& Erro de Transmissão da Informação (Kirwan soma dos erros de comunicação e \\
& consulta da informação de Baber \& Stanton) \\
\hline
\end{tabular}

\subsection{Princípios de Erro Humano}

Como mencionado abaixo, em geral, não existe uma forma garantida de tornar perfeitas as interações humano-computador a tal ponto que o Erro Humano seja impossível de acontecer. Por outro lado, há uma série de recomendações e princípios elaborados por designers que estudaram o comportamento dos usuários. Isso auxilia a projetar sistemas de interação que sejam mais fáceis de se utilizar e direcionam o usuário para um número reduzido de acidentes, para erros reversíveis, ou para erros cuja recuperação não prejudique o usuário. Nos itens a seguir, são compiladas as recomendações de Reason (1990), Norman (1983) e Rizzo, Ferrante e Bagnara (1995). Destaque-se a importância deste conteúdo para a pesquisa, pois é a partir dele que se construiu o critério de análise para criar os princípios.

\subsubsection{Resumo dos Princípios de Erro Humano}

Depois da revisão bibliográfica do conteúdo, percebeu-se que os princípios reunidos pelos autores, seguem uma linha em comum a respeito do que fazer, no caso de um designer de interação, para que o Erro Humano tenha o menor impacto na operação. Dos pesquisadores estudados, todos enfatizam a importância do feedback da informação na interface para o usuário. Eles também consideram que o Erro Humano é inevitável - o que precisa ser bem trabalhado é a recuperação do erro e a experimentação com a interface por parte do usuário. O quadro 5 resume as recomendações dos autores estudados. 


\subsection{Considerações a respeito do Erro Humano}

A análise das referências relatadas anteriormente indica que o estudo do Erro Humano busca compreender a causa para as diferentes variações da performance humana, bem como a explicar essa variabilidade. A intenção dos seus pesquisadores é encontrar meios de medir a qualidade da performance humana e classificar as variações no comportamento de um indivíduo. Em teoria, isso permite que acidentes que resultam em fatalidades possam ser estudados em retrospecto a fim de apontar, nos sistemas de interação, os defeitos que necessitam correção.

O estudo das referências também permitiu entender que as causas do Erro Humano na IHC não é único, nem singular. A variação da performance humana acontece por fatores contextuais na IHC, por exemplo, um acidente acontece não só por uma falha ativa (como um descuido), mas também por falhas latentes no sistema (precondições para que o acidente aconteça, como problemas no projeto do artefato). Apesar da denominação, o ser humano pode não ter "culpa" pelo resultado de um acidente, pois a pessoa não tem controle direto sobre todos os fatores que ocasionam o Erro Humano.

A correta abordagem para a correção de um sistema que apresenta falhas (que ocasiona situações de acidentes) requer a decomposição mais completa possível na cadeia de eventos que culminou no Erro Humano. Essa minúcia permite encontrar e isolar os defeitos do sistema com maior agilidade, permitindo, assim, agilizar as devidas providências para a correção do problema pelas pessoas envolvidas no gerenciamento e na manutenção dos sistemas de interação.

Percebe-se também que muitas vezes a solução mais duradoura para livrar os sistemas do Erro Humano não está somente no treinamento rigoroso de operadores, mas sim no design das interfaces (Woods et al., 2004). Cuidados como a modulação do feedback em múltiplos canais sensoriais, a redução da sobrecarga cognitiva e a exposição constante dos estados do sistema são essenciais para o design de interação humano-computador (Reason, 1990). 
Quadro 5 Resumo dos princípios de Erro Humano da IHC revisados.

\begin{tabular}{|c|c|c|}
\hline Norman (1988) & Rasmussen e Vicente (1987) & Rizzo, Ferrante e Bagnara (1995) \\
\hline Fornecer Feedback sempre & $\begin{array}{l}\text { "Experimentaç̧ão" é necessária para } \\
\text { familiarização }\end{array}$ & Tornar a ação mais perceptível \\
\hline Diferenciar ações para torná-las & & Usar feedback multissensorial \\
\hline distintas & $\begin{array}{l}\text { Fornecer feedback por meio do } \\
\text { sistema }\end{array}$ & Mostrar mensagens claras, com \\
\hline Fazer ações serem reversíveis & & conteúdo específico \\
\hline \multirow[t]{7}{*}{$\begin{array}{l}\text { Padronizar a hierarquia e o leiaute } \\
\text { do sistema }\end{array}$} & $\begin{array}{l}\text { Mostradores devem dar visuais do } \\
\text { estado da ação (permitida ou não) } \\
\text { Tornar o estado do sistema sempre } \\
\text { visível }\end{array}$ & $\begin{array}{l}\text { Prover um diário de atividades } \\
\text { Permitir comparações }\end{array}$ \\
\hline & $\begin{array}{l}\text { Projetar mostradores com resumo das } \\
\text { operações permitidas }\end{array}$ & $\begin{array}{l}\text { Disponibilizar resultados da ação o } \\
\text { mais cedo possível }\end{array}$ \\
\hline & $\begin{array}{l}\text { Criar padrões de interação para } \\
\text { forçar o usuário a agir de forma } \\
\text { "correta" }\end{array}$ & $\begin{array}{l}\text { Dar respostas específicas para o } \\
\text { usuário, logo após o erro }\end{array}$ \\
\hline & $\begin{array}{l}\text { Dar ao usuário referências } \\
\text { externas para solucionar um } \\
\text { problema }\end{array}$ & \\
\hline & $\begin{array}{l}\text { Exibir dados disponíveis para } \\
\text { ajudar na recuperação de erros }\end{array}$ & \\
\hline & $\begin{array}{l}\text { Atentar para que a informação } \\
\text { incorporada à interface sirva de } \\
\text { modelo mental }\end{array}$ & \\
\hline & $\begin{array}{l}\text { Fornecer dicas visuais externas } \\
\text { para memorização }\end{array}$ & \\
\hline
\end{tabular}

Note-se também a relevância do estudo de Erro Humano para outras áreas do design de interface, como o da usabilidade. As heurísticas de usabilidade de Nielsen (1994), por exemplo, têm paralelos notáveis com os princípios apresentados anteriormente, especialmente os de Norman (1988). Das dez heurísticas de Nielsen (1994), uma delas pede para que os sistemas tenham "consistência e padrões" na maneira como se organizam, da mesma forma que Norman (1988) aconselha.

$\mathrm{O}$ item 3 , a seguir, trata sobre o método de pesquisa onde o conteúdo sobre classificação e identificação de Erro Humano são utilizados para compor a estratégia de análise. Além disso, os princípios para a prevenção de erros, descritos anteriormente, são importantes para realizar a triangulação com as teorias de design de jogos digitais. 


\section{Método de Pesquisa}

A pesquisa é composta por três fases, sendo que elas seguem uma ordem específica e uma fase depende da conclusão da fase anterior. A figura 1, a seguir, ilustra o fluxo das etapas da pesquisa:

Figura 1 Diagrama das fases da pesquisa.

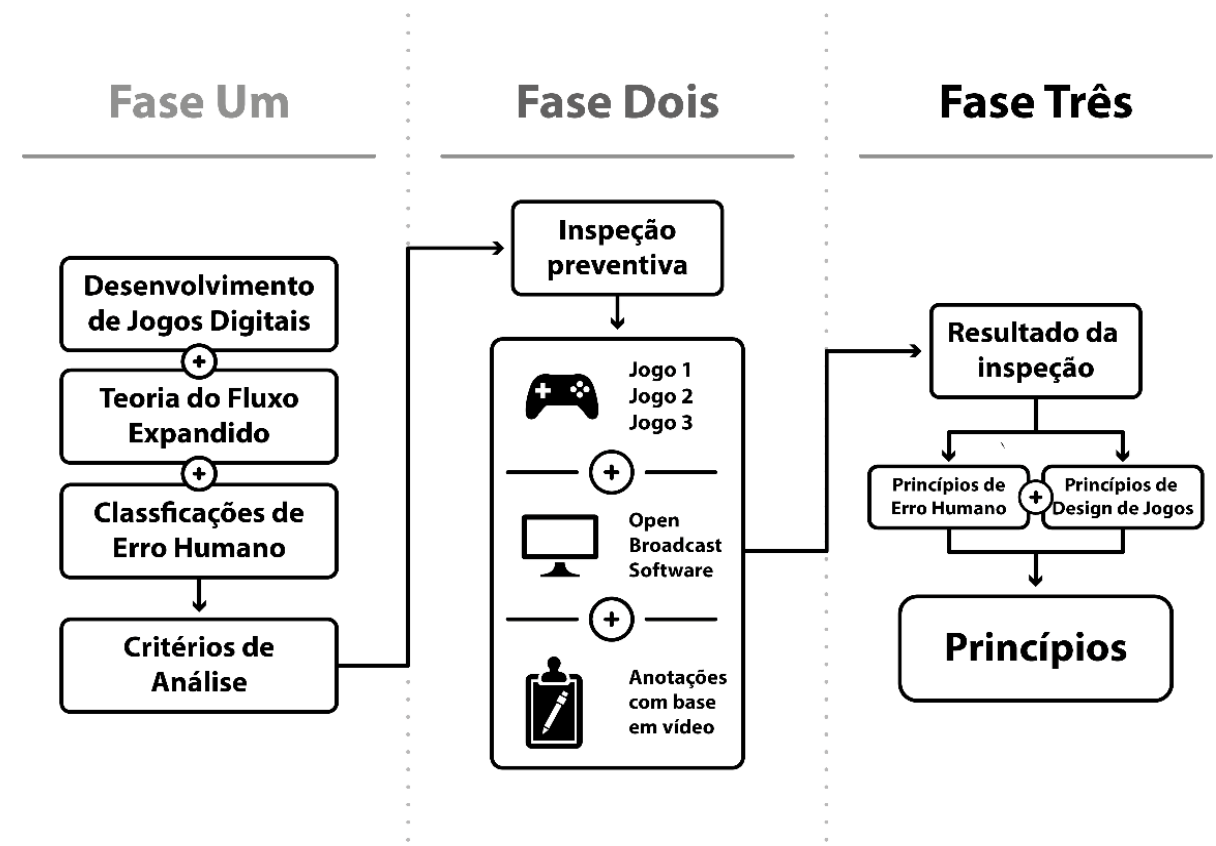

\subsection{Fase Um}

Coleta de dados referente à fundamentação teórica propriamente dita. Nesta etapa da pesquisa, foram estudados princípios, diretrizes, considerações da IHC sobre Erro Humano, bem como conceituação, características, causas, meios de identificação, classificações e princípios. Também foram estudadas teorias de design de jogos digitais, como a teoria do fluxo, a teoria das habilidades dos jogadores, $\mathrm{e}$ o modelo de desenvolvimento MDA. O objetivo de pesquisar esses assuntos foi de se municiar com o vocabulário e o conhecimento teórico necessário para identificar quais deslizes do jogador foram erros humanos, que componentes do design de jogos foram influentes nessas situações e se houve perda da motivação, ou seja, quebra do estado de fluxo do jogador. Nos próximos itens é feita uma breve descrição de cada uma das teorias pertinentes ao desenvolvimento de jogos digitais, que são retomadas no item 4 e estão ilustrados na figura 5 . 


\subsubsection{Teoria do Fluxo}

Teoria do Fluxo vem de um estudo da psicologia feito por Csikszentmihaly (1990) em que afirma que a diversão é fruto do equilíbrio entre as habilidades de um indivíduo e o desafio que ele enfrenta. Toda vez que uma pessoa está compenetrada em alguma atividade, em um estado parecido com um transe, segundo Csikszentmihaly (1990) "ela está em fluxo".

Para sair desse estado de fluxo, de acordo com Csikszentmihaly (1990) são necessárias duas condições: (1) o desafio exigir um nível de habilidade que a pessoa não tenha (o que torna a atividade estressante); (2) ou o indivíduo tem um nível de habilidade acima do necessário para o desafio proposto (o que proporciona uma situação de tédio para a pessoa). O ideal, para o design de jogos, é que o designer encontre uma forma de equilibrar os desafios no jogo com as habilidades do jogador.

\subsubsection{Habilidades do Jogador}

Habilidades do Jogador são um conjunto de capacidades cognitivas e psicomotoras as quais são necessárias para que um jogador possa efetivamente interagir com um jogo digital (Järvinen, 2008). Existem três qualidades para as habilidades, segundo Järvinen (2008), definidas da seguinte forma:

- Habilidades Não Aplicáveis: Habilidade que não tem relevância para o jogador na hora de jogar. Ex.: O jogador não precisa, necessariamente, saber caminhar para jogar Pac-Man.

- Habilidades Triviais: Habilidades cognitivas ou psicomotoras que foram adquiridas pelo jogador fora do contexto do jogo, mas podem ser aplicadas durante a interação. Ex.: Uma pessoa que sabe dirigir aplica seu conhecimento em um jogo de simulação de corrida.

- Habilidades Não-triviais: Habilidades cognitivas ou psicomotoras que o jogador não possui mas adquire à medida que interage com o jogo digital. Ex.: Quando o indivíduo compreende o funcionamento das regras de um jogo de cartas.

\subsubsection{O Modelo MDA}

O modelo MDA (Mechanics, Dynamics and Aesthetics) é uma proposta de formalização da definição de termos utilizados pela indústria de jogos digitais, além de um guia para o design de jogos, criada por Hunicke et al. (2004). Ele sugere que o designer deve projetar primeiro qual experiência estética que se deseja proporcionar para o jogador, ao invés de começar definindo quais funcionalidades o jogo possuirá. Segundo Hunicke et al. (2004), o modelo é composto 
por três partes: (1) Mecânicas - Regras que compõem o sistema do jogo; (2) Dinâmicas - A interação do jogador com o sistema; (3) Estéticas - A experiência que o jogador vivencia.

Em se tratando de Estéticas, considera-se a definição segundo Zangwill (2003): "o predicado 'estética' pode ser qualificado a uma série de termos: julgamentos, experiências, conceitos, propriedades ou palavras". Em outras palavras, o modelo MDA considera estética como experiência de jogo.

No MDA de Hunicke et al. (2004) é apresentada uma taxonomia de oito experiências estéticas. Ela serve como uma sugestão para o design de jogos:

1. Desafio: Jogo como corrida de obstáculos

2. Descoberta: Jogo como território inexplorado

3. Expressão: Jogo como forma de autoconhecimento

4. Fantasia: Jogo como faz-de-conta

5. Narrativa: Jogo como drama narrativo

6. Sensação: Jogo para o prazer dos sentidos

7. Sociedade: Jogo como comunidade

8. Sujeição: Jogo como passatempo

Em se tratando de Mecânicas, considerou-se a definição de Goodman (2010), além da definição de Hunicke et al. (2004). Para Goodman (2010) existem três tipos de mecânicas: (1) Mecânicas Básicas - Regras usadas repetidamente durante a partida de um jogo. Ex.: Mover peças em jogo de damas. (2) Mecânicas Primárias - Regras que usam as mecânicas básicas para se alcançar o objetivo geral do jogo. Ex.: "Comer" peças no jogo de damas. (3) Mecânicas Secundárias - Regras que facilitam o alcance do objetivo geral, mas não são obrigatórias que o jogador as use. Ex.: Quando a peça chega ao final de um tabuleiro ela se torna uma Dama, que pode se mover em todas as diagonais do tabuleiro.

\subsection{Fase Dois}

Estudo de campo na forma de inspeção preventiva de erro por meio de filmagem de partidas de jogos. Questões como tipos de erro encontrados, experiência estética percebida, tempo em que os erros foram identificados e quantidade de erros são alguns dos itens que foram apontados na análise. Os erros encontrados nessa fase também foram analisados de forma qualitativa, sendo feitos comentários sobre a relação do erro encontrado e o contexto do jogo no momento em que o erro foi identificado. 


\subsection{Fase Três}

2 Nota do autor: Segundo Azevedo, et al. (2013): "A triangulação significa olhar para o mesmo fenômeno, ou questão de pesquisa, a partir de mais de uma fonte de dados".
Cruzamento das teorias de Erro Humano e design de jogos. Depois de devidamente identificados quais são os Erros Humanos cometidos durante as sessões de jogos e a sua associação com a estética proposta para o jogo digital, foi realizada a triangulação ${ }^{2}$ das teorias de Erro Humano e da teoria do Fluxo Expandido se utilizando de um critério de análise para melhor relacionar os dados, critério esse que tem como base as teorias de design de jogos. A representação dessa sobreposição de ideias foi feita por meio de princípios.

\subsection{Técnicas de coleta}

3 Tradução livre feita pelo autor de Embrey (1993, p. 336): is the process via which specific errors associated with tasks or task steps are identified.
Para a coleta de dados foi utilizada a técnica de Embrey (1993, pág. 336) denominada PHEA, ou Predictive Human Error Analisys, adaptada para observação de jogos digitais. Segundo o autor, "esse é o processo pelo qual erros específicos associados a tarefas ou etapas em

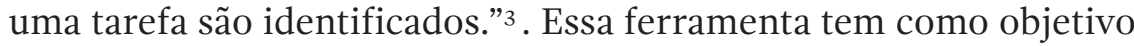
identificar erros cuja consequência é de risco para o ser humano. Além disso, a triangulação de teorias foi utilizada para estabelecer relações entre questões de design de jogo e Erro Humano.

\subsubsection{Inspeção Preventiva de Erros}

Essa técnica está presente no modelo de análise de Embrey (1993, pág. 329), denominado SPEAR, ou System For Predictive Error Analysis And Reduction, porém adaptada para a observação de jogos digitais. Segundo o autor, a SPEAR tem como objetivo identificar fontes de risco para o ser humano e avaliar a segurança em sistemas como os de uma usina nuclear.

Levando em consideração que o sistema sendo inspecionado são jogos digitais, algumas adaptações ao método SPEAR foram necessárias. Para Embrey (1993, pág. 333), por exemplo, durante a análise, é necessário considerar os possíveis riscos mais perigosos para o ser humano durante a interação com o sistema para futura avaliação, ao passo que, nos jogos digitais esses riscos não afetam o jogador diretamente, mas sim o seu avatar digital. Nos jogos digitais ocorrem, frequentemente, situações onde o personagem jogável do usuário sofre as consequências do erro do jogador e, assim, condicionam o fim de jogo. Logo, o que foi observado durante a inspeção foram apenas situações em que o jogador agiu de forma a causar o fim do jogo.

Para conduzir uma inspeção preventiva de erros, Embrey (1993, pág. 336) afirma que há 4 procedimentos para identificar erros: (1) Definição do nível de detalhamento da análise, (2) Análise de erro de planejamento, (3) Análise de erro de operação e (4) Análise de recuperação. Os procedimentos utilizados na inspeção conduzida 
neste projeto foram apenas o número (1), pois foram analisados tipos de erros além dos citados por Embry (1993, p. 336). Incluso a esses procedimentos estão as análises das estéticas do modelo MDA de Hunicke et al. (2004).

\subsubsection{Triangulação}

Esta técnica consiste em observar um fenômeno utilizando múltiplas fontes de dados, tanto qualitativas, quanto quantitativas, a fim de se obter um novo posicionamento sobre determinado assunto (Azevedo, et al. 2013). No presente projeto, a triangulação foi usada de forma a unir teorias, segundo Duarte (2009) esse tipo de uso tem como objetivo "interpretar um conjunto de dados de um estudo, verificando-se a sua utilidade e capacidade". Entende-se que este é um método útil para a pesquisa, uma vez que se procura relacionar os princípios de design com base no Erro Humano com o design de jogos.

\subsection{Amostra}

Para efetuar a coleta dos dados, o tamanho da amostra foi de 3 jogos digitais, desenvolvidos por empresas diferentes. A seleção dos jogos levou em consideração os seguintes critérios:

A. O jogo deve ter sido desenvolvido entre os anos de 2010 a 2015;

B. O jogo deve ter a derrota como uma mecânica recorrente durante a sessão de jogo.

C. O jogador deve ter familiaridade com os jogos escolhidos, tendo jogado no mínimo 5 horas de cada jogo.

Observa-se que apesar de todos os jogos terem mecânicas que condicionam a derrota do jogador, ou o término do jogo, nem todos têm essa mecânica relacionada à experiência estética de forma explícita. Logo, o segundo critério (letra "B") foi incluído no processo

4 Nota do autor: Plataforma é o termo que se atribui ao hardware utilizado para fazer o software do jogo funcionar. de seleção apenas para facilitar a pesquisa dos erros.

O quadro 6 apresenta os jogos selecionados para a amostra. Eles foram organizados utilizando os seguintes rótulos: Nome | Desenvolvedora | Distribuidora | Ano de Lançamento | Plataforma ${ }^{4} \mid$ Relevância para o projeto.

\subsection{Perfil do Participante}

Segundo pesquisas da ESA (Entertainment Software Association) e da Insidecom de 2012, a faixa etária em média do jogador americano e brasileiro, é de 25 anos; e segundo Reason (1993), erros acontecem em maior parte com usuários experientes. Sendo assim, para a escolha do participante da etapa de inspeção da Fase Dois é necessário que se possua no mínimo 10 anos de experiência com jogos digitais e se esteja na faixa etária dos 25 anos. 
Decidiu-se por escolher o pesquisador como executor da inspeção, pois o mesmo se enquadra nos requisitos identificados acima.

Entende-se que não há risco de os dados coletados serem parciais, a não ser que o pesquisador erre propositalmente durante a gravação das sessões de jogo. Considera-se, também, que independente de quem estiver jogando, os erros irão acontecer.

\subsection{Estratégia de Análise}

O processo de análise dos jogos digitais selecionados ocorreu em três momentos. O primeiro envolveu a gravação de sessões de jogo que durarão 30 minutos para cada título. O segundo se referiu à inspeção dos vídeos gravados, se utilizando de uma série de critérios de análise. O terceiro foi referente à triangulação das teorias de design de jogos, os princípios de Erro Humano e os resultados da pesquisa. A figura 1 esquematiza o processo de coleta de dados.

\subsubsection{Gravação}

5 Nota do autor: $\mathrm{E}$ interessante observar que o software proposto para coleta de dados é gratuito.
O jogador iniciou uma partida nos jogos escolhidos para análise durante 30 minutos, quando o tempo acabou, o jogador fechou o jogo. A escolha de um jogador experiente em partidas com os jogos da amostra, ou seja, um jogador que não requer treinamento, viabiliza que se grave apenas uma partida. A sessão de cada jogo foi gravada e armazenada em hardware utilizando-se dos seguintes recursos:

(1) Computador Pessoal com sistema operacional Windows 7; (2) Controlador de jogo X-Box 360 para Windows; (3) Monitor de 21 polegadas; e (4) Software Open Broadcaster Software (para gravação de vídeos no computador). 
Quadro 6 Jogos selecionados para análise

\begin{tabular}{|c|c|c|c|}
\hline Nome & Dark Souls 2: Scholar of the First Sin & Darkest Dungeon & Hearthstone \\
\hline Desenvolvedora & From Software & Red Hook Studios & Blizzard Entertainment \\
\hline Distribuidora & Bandai Namco Games & $\begin{array}{l}\text { Não Possui } \\
\text { (jogo independente) }\end{array}$ & Activision \\
\hline Anode Lançamento & 2015 & 2015 & 2014 \\
\hline Plataforma & $\begin{array}{l}\text { Windows PC, X-Box One, X-Box } \\
360, S_{3} \text { e PS4. }\end{array}$ & Windows PC, Mac OS. & $\begin{array}{l}\text { Windows PC, Mac OS, iOS } \\
\text { e Android. }\end{array}$ \\
\hline $\begin{array}{l}\text { Relevéncia para o } \\
\text { projeto de } \\
\text { pesquisa }\end{array}$ & $\begin{array}{l}\text { O nivel de dificuldade que o } \\
\text { jogo impcõe ao jogador é } \\
\text { relevante para o projeto. } \\
\text { Segundo o criador, Hidetaka } \\
\text { Miyazaki, as principais } \\
\text { experiências do jogo são o } \\
\text { medo e o pavor, traduzidas } \\
\text { na forma de mecanicas que } \\
\text { punem as falhas do jogador. }\end{array}$ & $\begin{array}{l}\text { O jogo tem relevância } \\
\text { não só pelo aspecto da } \\
\text { dificuldade,mas também } \\
\text { porter sido um jogo } \\
\text { independente financiado } \\
\text { de forma colaborativa. A } \\
\text { independência do jogo de } \\
\text { tendências ditadas pelo } \\
\text { mercado abre diferentes } \\
\text { perspectivas de analise. }\end{array}$ & $\begin{array}{l}\text { A relevancia do jogo está } \\
\text { na qualidade e na } \\
\text { popularidade. Considerado } \\
\text { o melhor jogo para } \\
\text { dispositivos móveis pela } \\
\text { Game Design Conference } \\
\text { de } 2014 \text {, o jogo possui } \\
\text { mais de } 25 \text { milhões de } \\
\text { jogadores }{ }^{1} \text { em ambas as } \\
\text { plataformas iOS e Android. }\end{array}$ \\
\hline
\end{tabular}

\subsubsection{Inspeção Preventiva de Erro dos Jogos Digitais}

Após a gravação, os vídeos foram analisados sistematicamente. A técnica escolhida para a coleta dos dados requer que existam critérios para a análise do fenômeno, para tanto, o sistema para protocolar os dados respeitou os seguintes critérios de análise: (1) Qual é o objetivo que o jogador escolheu alcançar durante a sessão gravada? (2) Segundo a taxonomia de Hunicke et al (2004), quais são as estéticas identificadas durante a sessão? (3) Segundo a classificação de erros de Baber \& Stanton (1996) e Kirwan (1998), quais são os erros identificados? (4) Segundo a classificação de erros de Reason (1990), em quais níveis de comportamento - do modelo SRK são encontrados erros? (5) Quantas vezes e quando esses erros foram encontrados?

O objetivo, dentro do jogo, que está sendo observado na análise foi escolhido pelo próprio jogador. Durante a gravação da sessão em vídeo não foi pedido que o jogador seguisse qualquer tipo de instrução, a não ser que jogasse durante os 30 minutos do tempo de observação.

A taxonomia do modelo MDA (Hunicke et al. 2004) foi utilizada como critério para análise, pois a triangulação seria facilitada à medida que se conhecia a experiência estética do jogo. Para encontrar a estética 'correta', se utilizou como base a descrição de cada item da taxonomia, descrita por Hunicke et al. (2004). Priorizou-se a estética somente em detrimento das dinâmicas e mecânicas, pois ela é a primeira "camada" do jogo que o usuário percebe. Além disso, era esperado encontrar a relação entre o Erro Humano e a experiência do jogador com a triangulação desses dados. 
As classificações de Erro Humano escolhidas para análise foram selecionadas mediante revisão da bibliografia. Os autores escolhidos, Reason (1990), Baber \& Stanton (1994) e Kirwan (1996), classificam os tipos de erros de formas particulares, entretanto partindo de uma mesma base teórica e de processos semelhantes, o que permiteu que uma gama maior de erros pudessem ser identificados durante a observação. A quantidade de erros observados e a marcação de quando eles aconteceram foram registrados com auxílio de um programa de reprodução de vídeos, sendo que cada vez que um erro fora identificado, a reprodução do vídeo era pausada e era feita uma leitura do tempo da reprodução, como no exemplo da figura 2. Em seguida, o tipo de erro, os minutos e os segundos nos quais o erro foi identificado eram anotados com lápis e papel. Os resultados anotados, então, foram relacionados em uma tabela como o exemplo do quadro 7.

Ressalte-se que o processamento desses dados foi feito apenas observando os vídeos gravados. Nenhum dado foi coletado durante as sessões do jogo para evitar que os resultados pudessem ser influenciados, uma vez que o jogador poderia agir de forma a produzir erros de propósito. A intenção foi coletar o Erro Humano, que acontece por acidente, de forma inesperada. No próximo item, os vídeos gravados são descritos e o tempo em que os erros foram identificados foi apontado para facilitar a compreensão do que está sendo estudado nessas sessões. Além disso, estão apresentados os dados coletados, a triangulação das teorias e a apresentação dos princípios com base nos princípios apresentados no item 2.2.1.

Figura 2 Exemplo de como é observado o tempo em que ocorre a identificação do erro.

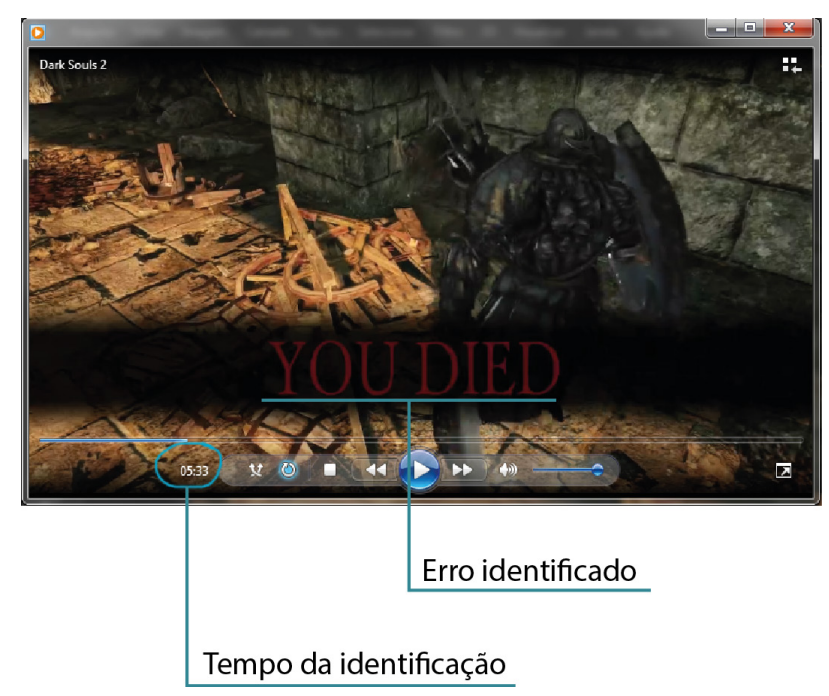




\subsubsection{Triangulação dos dados coletados}

O terceiro e último momento do procedimento de análise é a triangulação de teorias. Depois de colhidos os dados sobre o Erro Humano nos jogos digitais, por meio da inspeção, foi composta uma matriz com os resultados, estabelecendo relações entre o comportamento do jogador, com base no modelo SRK (Rasmussen, 1989), suas habilidades (Järvinen, 2008), as estéticas (Hunicke et al., 2004) encontradas nas gravações, os tipos de erros (Baber \& Stanton, 1996 e Kirwan, 1998), os tipos de mecânicas presentes nos jogos (Goodman, 2010).

No item 4 é abordado o resultado da análise que se conduziu utilizando o método de coleta descrito nos itens anteriores. Além de serem apresentadas as inspeções resultantes, o item 6 também mostra a formulação dos princípios, por meio da triangulação dos dados coletados se utilizando dos princípios de Erro Humano e das teorias de design de jogos.

Quadro 7 Exemplo de tabela para relação do tipo, tempo e quantidade de erros observados na gravação.

\begin{tabular}{lll}
\hline Tipos de Erro de Baber \& Stanton (1994) e Kirwan (1996) & Tempo & Quantidade \\
\hline Erro de Leitura & ??m??s & ?? \\
\hline Erro por Omissão & ??m??s & ?? \\
\hline Erro de Planejamento & ??m??s & ?? \\
\hline Erro de Qualidade da Ação & ??m??s & ?? \\
\hline Erro de Seleção & ??m??s & ?? \\
\hline Erro de Sequencia & ??m??s & ?? \\
\hline Erro de Tempo & ??m??s & ?? \\
\hline Erro de Transmissão da Informação & ??m??s & ?? \\
\hline & & \\
\hline Tipos de Erro de Reason (1990) & Tempo & Quantidade \\
\hline Erros no nível das Perícias & ??m??s & ?? \\
\hline Erros no nível das Regras & ??m??s & ?? \\
\hline Erros no nível do Conhecimento & ??m??s & ?? \\
\hline
\end{tabular}

\section{Resultado das Análises}

No item 4.1, são descritas as sessões dos jogos gravadas, descrevendo qual o objetivo do jogador dentro do jogo, quais as principais mecânicas presentes, as experiências estéticas percebidas e os erros identificados. Esses dados são depois compilados em uma tabela para resumir a análise. No item 4.2 são apresentados os 
6 Uma nova partida geralmente se refere à primeira interação do jogador com o sistema, onde o usuário não tem familiaridade com o jogo. princípios para o design de jogos digitais, derivadas da análise dos dados coletados, assim como um comentário de como cada uma delas pode ser aplicada em projetos de jogos. Para melhor compreender a descrição dos vídeos, no final do artigo se encontra um endereço da internet no qual é possível acessá-los.

\subsection{Dados Coletados}

A inspeção dos vídeos gravados é descrita de acordo com a seguinte ordem:

1. O objetivo do jogador durante a sessão;

2. As mecânicas principais;

3. As experiências estéticas;

4. Os erros identificados de uma forma geral e o tempo em que ocorreram.

Apresenta-se também um resumo dos dados coletados na forma de um quadro. Os dados obtidos são protocolados nesse quadro de acordo com a lógica proposta na estratégia de análise explicada no subitem 3.6. Começar uma nova partida ${ }^{6} \mathrm{em}$ cada um dos jogos não foi uma etapa necessária para a coleta de dados desta pesquisa, a observação do erro ocorre em partidas onde o jogador já jogou o jogo. Se supôs que a familiaridade com o sistema resulte em erros cuja definição se alinha com aquela estudada na revisão de literatura.

4.2 Resultado da Inspeção: Jogo 1 - Dark Souls 2: Scholar of the First Sin

\subsubsection{Objetivo}

O objetivo do jogador foi o de derrotar um inimigo específico, chamado "The Pursuer". Durante os 30 minutos da gravação, o jogador falhou oito vezes em cumprir sua missão - em cada falha, se chegou ao estado de "Fim de Jogo" (representado pelo texto em vermelho "YOU DIED" na interface do jogo). O jogador não obteve sucesso no seu objetivo durante a partida.

\subsubsection{Mecânicas do Jogo}

O jogo apresenta uma série de mecânicas básicas que são frequentemente utilizadas, durante a sessão, para se alcançar o objetivo: (1) Controle dos movimentos do avatar do jogador; (2) Ataque fraco / forte; (3) Esquiva; (4) Bloqueio; (5) Aparo; (6) Travar mira; (7) Corrida. As mecânicas primárias do jogo têm relação direta com o uso dessas mecânicas básicas e frequentemente ajudam o 
jogador a alcançar seus objetivos. São elas: (1) Utilizar equipamentos (armas, armaduras, acessórios); (2) Consumir itens (poções de cura). Já as mecânicas secundárias são opcionais para se alcançar o objetivo do jogo, mas auxiliam o jogador permitindo: (1) Atacar pelas costas do inimigo; Atacar em resposta (depois de um aparo); (2) Invocar outros jogadores; (3) Escrever mensagens e ler aquelas deixadas por outros jogadores; (4) Subir de nível; (5) Potencializar equipamentos.

\subsubsection{Experiências Estéticas}

7 Em Dark Souls 2 - Scholar of the First Sin, durante a sessão em que o jogador invoca outros usuários, é possível que os jogadores se comuniquem por meio de microfones, entretanto, durante a sessão observada, nenhum jogador possuía microfone e se comunicavam por meio de gestos pré-determinados pelo sistema.

8 Em Dark Souls 2 - Scholar of the First Sin, durante a sessão em que o jogador invoca outros usuários, é possível que os jogadores se comuniquem por meio de microfones, entretanto, durante a sessão observada, nenhum jogador possuía microfone e se comunicavam por meio de gestos pré-determinados pelo sistema.
As experiências estéticas observadas foram coletadas conforme a definição das taxonomias de Hunicke et al. (2008). A seguir, além de enumerar as estéticas encontradas, se faz uma breve explicação de como elas se manifestam durante a sessão:

- Desafio - O jogador é apresentado a uma série de obstáculos representados pelos inimigos (unidades controladas pela inteligência artificial do jogo), espalhados pelo espaço virtual do jogo. O objetivo dessas entidades é impedir que o jogador prossiga.

- Fantasia - O jogador "faz de conta" que é o personagem que aparece no jogo. O usuário não só controla suas ações e seu destino, mas também se projeta no personagem na forma como aborda as situações dentro do jogo.

- $\quad$ Sociedade - O jogador encontra, no espaço do jogo, uma série de sinais deixados por outros jogadores. Os sinais laranja significam mensagens que podem ajudar o progresso na partida. Os sinais brancos significam que o jogador pode invocar outros usuários para a sua sessão. Uma vez que os jogadores se encontram conectados virtualmente, eles podem interagir entre si e com o mundo do jogo, com a intenção de progredir na partida ${ }^{7}$.

- Sujeição - É a principal estética do jogo segundo seus criadores $\left(\right.$ web, $\left.2011^{8}\right)$. A estética de sujeição, segundo Hunicke et al. (2008), tem relação à forma como o jogador se sujeita à atividade de jogar, apesar da dificuldade, da frustração e do fracasso. Dark Souls 2 pune o jogador, mas ele se submete a atividade de jogar, pois acredita na possibilidade de vencer.

\subsubsection{Classificação dos Erros Identificados}

Durante a inspeção, foram identificados na gravação uma série de erros cometidos pelo usuário: Erros de leitura, de ação e de planejamento (Baber \& Stanton, 1996); erros de tempo e qualidade da ação (Kirwan, 1998); e erros no nível das perícias, regras e do conhecimento (Reason, 1990). O quadro 8 apresenta o número de erros encontrados e o tempo no qual eles aconteceram. 
Quadro 8 Incidência e registro do tempo dos tipos de erro no jogo Dark Souls 2: Scholar of the First Sin.

\begin{tabular}{llc}
\hline Tipos de Erro de Baber \& Stanton (1994) e Kirwan (1996) & Tempo & Quantidade \\
\hline Erro de Leitura & 01mo5s; 04m30s; 10m44s; 15m57s & 5 \\
\hline Erro de Planejamento & 14m22s; 19m56s; 28m10s & 3 \\
\hline Erro de Qualidade da Ação & oom40s; 01m26s; 06m23s & 3 \\
\hline Erro de Tempo & 01m26s; 05m17s; 06m24s; 10m36s; & 12 \\
& $\begin{array}{l}11 \mathrm{~m} 40 \mathrm{~s} ; \text { 14m33s; 19m56s; 22m39s; } \\
\text { 23m33s; 23m51s; 26m26s; 31m03s }\end{array}$ \\
\hline & & \\
\hline
\end{tabular}

Durante a sessão, a maior parte dos erros observáveis foi do tipo erro de tempo. Nessas situações, é possível ver o jogador fazendo ações no momento errado, ou utilizando ações erradas. A observação indica que os erros no nível das perícias estão diretamente relacionados com a incidência de erros de tempo, de qualidade da ação e de leitura, por exemplo, quando o jogador erra um golpe, ou ataca mais de uma vez, ao invés de se esquivar. Erros no nível das regras se relacionam aos erros de leitura, uma vez que o jogador fez a leitura errada de quantos inimigos o cercam.

A partir do tempo 10m45s, percebeu-se que o jogador começa a se adaptar aos desafios do jogo, deixando de cometer erros no nível das perícias, regras e conhecimento. Isso significa que o jogador aprendeu a solucionar os desafios impostos até chegar no objetivo principal, a luta com o inimigo "The Pursuer". Essa adaptação é característica das habilidades não-triviais sendo desenvolvidas à medida que a sessão prossegue, significando que, enquanto jogava, o usuário estava em fluxo (Csikszentmihalyi, 1990; Järvinen, 2008). De qualquer forma, o jogador não se adaptou bem o suficiente para que ele pudesse ser bemsucedido no seu objetivo de derrotar o inimigo "The Pursuer".

\subsection{Resultado da Inspeção: Jogo 2 - Darkest Dungeon}

\subsubsection{Objetivo}

O jogo é sobre um grupo de mercenários comandados pelo jogador que tem como objetivo recuperar os tesouros de uma mansão. O jogo tem missões nas quais os personagens podem saquear dinheiro e relíquias para melhorar suas habilidades e equipamentos. Durante a 
sessão, o jogador selecionou duas missões para serem cumpridas pelo seu grupo de mercenários virtuais. A intenção era ser bem-sucedido nas missões e manter todos os integrantes vivos, entretanto o jogador não conseguiu cumprir nenhum de seus objetivos e ainda perdeu 3 de suas unidades enviadas para o combate.

\subsubsection{Mecânicas}

O jogo apresenta mecânicas básicas que envolvem o controle dos movimentos e a seleção das habilidades dos personagens do jogador. Como mecânicas primárias, o jogo possui dois estados, o de combate (onde o jogador precisa selecionar as habilidades de seus mercenários a fim de vencer os desafios) e o de exploração (onde o jogador explora o espaço do jogo). As mecânicas secundárias envolvem a fuga do combate, a desistência da missão, a administração de recursos e o monitoramento do estado dos personagens controlados pelo jogador.

\subsubsection{Experiências Estéticas}

O pano de fundo que caracteriza a experiência do jogo é a sua intenção de aterrorizar o jogador e mantê-lo sob pressão durante a partida. O primeiro parágrafo do texto que aparece na tela inicial do jogo já avisa que o jogador falhará. No início do jogo, a tela inicial apresenta para o jogador o seguinte texto: “ Darkest Dungeon é sobre tirar o melhor de uma situação ruim. Missões vão falhar ou devem ser abandonadas. Heróis morrerão, e quando morrerem, será para sempre. Progresso é salvo automaticamente, então ações são permanentes. " Esse parágrafo já informa que tipo de experiências estéticas os designers projetaram para o jogo.

- Desafio - O jogador é desafiado a comandar uma expedição de mercenários a uma masmorra (no mundo do jogo) de onde deve sair vitorioso. A forma randômica como os inimigos aparecem no caminho do avatar do jogador e como o combate procede exigem que o jogador se adapte rápido aos estados do sistema a fim de não falhar.

- Fantasia - O jogador faz de conta que é o comandante de um grupo de mercenários com a missão de limpar as masmorras e recuperar a mansão do contratante (personagem do jogo). Existe também um efeito de fantasia no jogo nas oscilações do estado mental dos personagens jogáveis, que "se estressam" e eventualmente sucumbem a pressão de andar por um calabouço escuro, cheio de armadilhas e vilões.

- Narrativa - A experiência narrativa se manifesta na presença do narrador do jogo que, ao narrar o que acontece na partida, acentua o drama que o jogador passa. 
- Sujeição - Assim como no jogo observado no item anterior, a experiência de sujeição é parte principal da estética do jogo, uma vez que o jogador se sujeita à derrota dos personagens que controla (derrota já insinuada pelo texto introdutório do jogo).

\subsubsection{Classificação dos Erros Identificados}

Durante a inspeção foram identificados erros de planejamento, de seleção (Baber \& Stanton, 1996); de transmissão da informação (Kirwan, 1998); erros no nível das regras e no nível do conhecimento (Reason, 1990). O quadro 9 apresenta o tempo no qual os erros foram identificados e sua quantidade.

Quadro 9 Incidência e registro do tempo dos tipos de erro no jogo Darkest Dungeon.

\begin{tabular}{lll}
\hline Tipos de Erro de Baber \& Stanton (1994) e Kirwan (1996) & Tempo & Quantidade \\
\hline Erro de Planejamento & 02m20s; 03m39s; 21m49s; 26m45s & 4 \\
\hline Erro de Seleção & ogmo4s; 26m10s; 28m26s; 29m47s & 4 \\
\hline Erro de Transmissão da Informação & oom40s; 01m26s; 06m23s & 5 \\
\hline & & Quantidade \\
\hline Tipos de Erro Reason (1990) & Tempo & 3 \\
\hline Erro no nível de regra & ogm50s; 18m30s; 22m24s & 3 \\
\hline Erro no nível de conhecimento & o8m12s; 26m45s; 28m22s & 3 \\
\hline
\end{tabular}

Notou-se que o design da interface do jogo acabou causando alguns erros, os quais o jogador não era responsável. A organização da informação e o posicionamento de alguns botões que regem mecânicas primárias não estavam bem claras, especialmente a que se referia à opção de fugir das batalhas. Se o jogador soubesse da localização dessa função, as falhas teriam sido evitadas. O problema está na posição e clareza desse botão na interface gráfica, em uma situação fora de combate, o botão (representado por um quadrado vermelho com uma bandeira branca no meio) se encontra no canto superior esquerdo da tela (figura 3) e durante o combate, ele aparece junto ao mapa (figura 4).

De acordo com os princípios de Norman (1988), o designer deve projetar uma interface para o sistema "que considere o que o usuário pode utilizar e como o sistema apresenta suas ferramentas para que sejam utilizadas". No que diz respeito ao Erro Humano, o problema encontrado na interface deste jogo é relativo ao sistema e não tem relação com o desafio do jogo, nem com seu design. Por essa razão a interface precisaria ser corrigida pelos desenvolvedores. 
Figura 3 Posição do botão de fuga durante a exploração no jogo Darkest Dungeon.

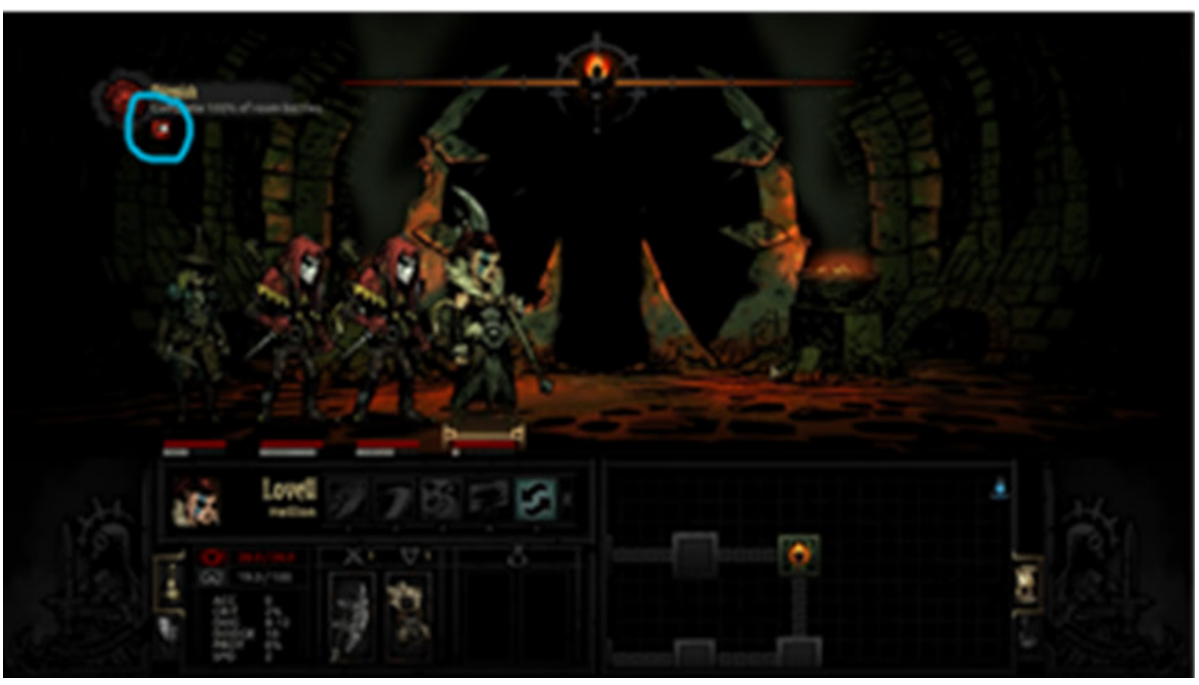

Figura 4 Posição do botão de fuga durante o combate no jogo Darkest Dungeon.

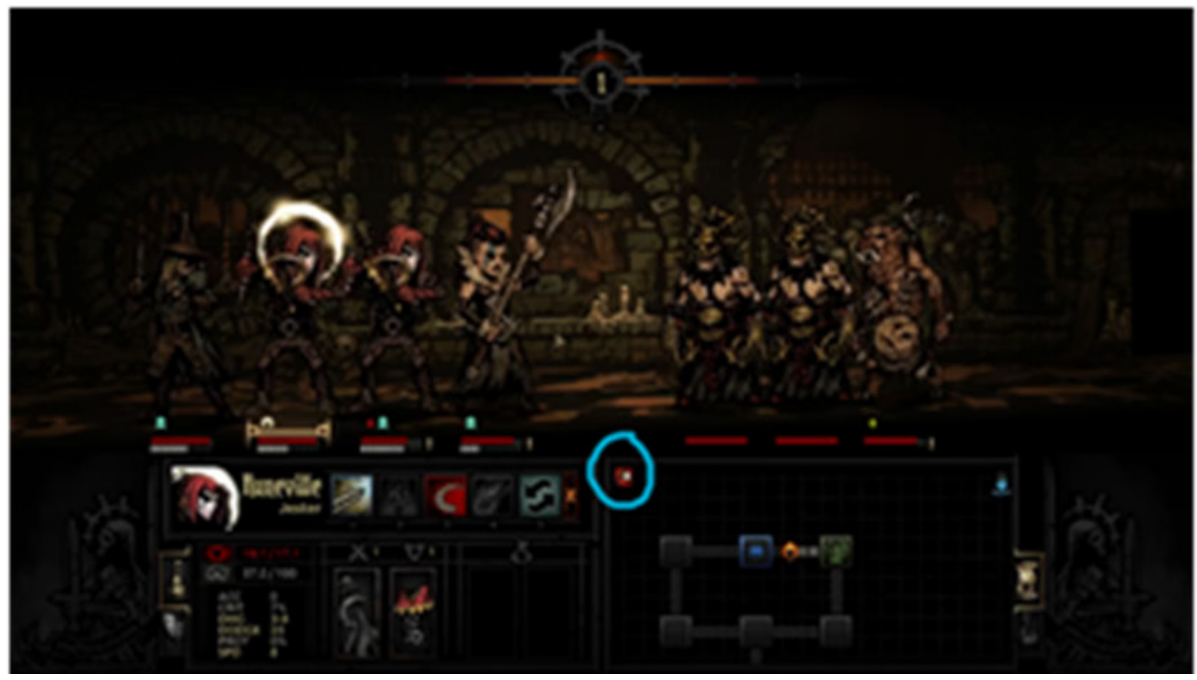

4.4 Resultado da Inspeção: Jogo 3 - Hearthstone: Heroes of Warcraft

\subsubsection{Objetivo}

O objetivo do jogo consiste em um jogador conseguir derrotar o outro. Cada jogador possui 30 "pontos de vida" que quando acabam, condicionam a vitória de um dos participantes. Esses pontos são reduzidos com a utilização, até o fim, de um baralho de cartas (deck). 


\subsubsection{Mecânicas}

O sistema do jogo apresenta três mecânicas básicas: (1) O jogo se divide em turnos que se alternam entre os jogadores; (2) A cada turno, os jogadores podem comprar uma carta do seu baralho e coloca-las na sua mão; (3) No seu turno, cada jogador pode colocar as cartas da sua mão na mesa; (4) Quando a carta estiver na mesa, o jogador pode seguir as regras escritas nas cartas para atacar o jogador adversário, a fim de vencer o jogo.

As cartas, por sua vez, possuem um conjunto de três mecânicas primárias que condicionam o seu uso, representadas no desenho da interface: (1) O "custo" para poder colocar a carta na mesa; (2) Os "pontos de vida" da carta; (3) Os "pontos de ataque" da carta. Ainda como parte das mecânicas primárias, o jogador pode utilizar as cartas para os seguintes efeitos: (1) Para atacar o adversário; (2) Para atacar outras cartas na mesa.

Além dessas características (custo, pontos de vida e ataque), as cartas possuem uma série de mecânicas secundárias que impõem condições ao funcionamento das cartas e que permitem a criação de estratégias pelo jogador. Seguem descritas a seguir: (1) Enfurecer: Quando uma carta é atacada, essa mecânica ativa algum efeito extra, por exemplo, quando atacada a carta com "enfurecer" aumenta o valor do seu ataque em 2 pontos; (2) Provocar: As cartas do adversário que estiverem no campo só podem atacar a carta com "provocar"; (3) Furtivo: A carta não pode ser alvo de ataques de cartas do adversário.

\subsubsection{Experiências Estéticas}

De acordo com o que foi observado no vídeo gravado e seguindo a taxonomia de Hunicke et al. (2008), a forma como o jogo se apresenta para o jogador, assim que a partida inicia, os sons, as músicas e o cenário proporcionam uma série de experiências estéticas descritas a seguir.

- Desafio - O jogador tem como objetivo derrotar um adversário utilizando um baralho de cartas que ele próprio organizou. Com sorte e estratégia, ele pode conseguir alcançar seu objetivo. $\mathrm{O}$ fato de os dois jogadores possuírem "pontos de vida” estabelece uma relação de competição entre eles, para ver quem consegue reduzir os pontos de vida do outro a zero primeiro.

- Fantasia - No início da gravação, um narrador dá "as boasvindas" ao jogador, na intenção de estabelecer a ilusão de que, quando o jogador inicia o jogo, ele está entrando em um lugar onde as pessoas esperam com ansiedade por duelos entre os jogadores. Durante a partida, a cada ataque, se pode ouvir os sons de uma plateia imaginária que assiste ao jogo. Todos esses recursos visuais e sonoros fazem emergir a estética de fantasia. 


\subsubsection{Classificação dos Erros Identificados}

Durante a sessão se observou que a maior parte dos erros identificados foram de planejamento e de seleção (Baber \& Stanton, 1996; Kirwan 1998); e no nível do conhecimento (Reason 1990). É possível observar que os erros de planejamento e no nível das regras começam a aparecer depois do minuto $12 \mathrm{~m} 30$ da gravação, dado que o jogador não conhecia as cartas que compunham o baralho escolhido e, portanto, ele cometeu erros que o levaram à derrota. $\mathrm{O}$ quadro 10 apresenta os erros identificados, a quantidade e o tempo em que ocorreram.

Outro fator que pode ser atribuído aos erros identificados (especialmente os de seleção) é a interatividade com o cenário da mesa. No minuto 07m57s, o jogador parece mais preocupado em interagir com os elementos desenhados no cenário do que em vencer o adversário, o que leva a realizar jogadas ruins que o conduzem a derrota. Caso tivesse focado na partida em andamento, o jogador poderia ter vencido.

Apesar dos elementos interativos no cenário não terem um impacto direto sobre o estado do sistema, percebe-se que os desenvolvedores do jogo os colocaram no cenário com a intenção de atrair a atenção do jogador enquanto o adversário faz a sua jogada. Como Hearthstone é um jogo online, o andamento da partida depende da ação dos usuários, quando um deles demora a jogar, o outro pode interagir com esses elementos para não se entediar.

Quadro 10 Incidência e registro do tempo dos tipos de erro no jogo Hearthstone: Heroes of Warcraft.

\begin{tabular}{lll}
\hline Tipos de Erro de Baber \& Stanton (1994) e Reason (1990) & Tempo & Quantidade \\
\hline Erro de Leitura & 15m22s; 28m23s & 2 \\
\hline Erro de Planejamento & 12m30s; 15m22s; 23moos; 28m23s; 33m42s & 5 \\
\hline Erro de Seleção & 02m43s; 12m30s; 25m15s; 33m42s & 3 \\
\hline & & \\
\hline Tipos de Erro Reason (1990) & Tempo & Quantidade \\
\hline Erro no nível do Conhecimento & 12m30s; 15m22s; 16m12s; 28m23s; 33m42s & 5 \\
\hline
\end{tabular}

\subsection{Resumo dos dados coletados}

Após observar os três jogos digitais e analisar sistematicamente e detalhadamente os vídeos, pôde se perceber o quanto as experiências estéticas pretendidas para o design do jogo influem na complexidade do sistema e na forma como o Erro Humano acontece. Nos dois primeiros jogos analisados, a estética de sujeição foi a mais importante para a experiência, visto que os designers do jogo atribuem essas características na descrição de seu próprio produto. Sendo assim, os 
desenvolvedores se aproveitam do estigma do Erro Humano (o medo de errar) para criar suas experiências. Já no terceiro jogo, percebe-se que não é a antecipação ao erro que importa para a experiência do jogador, mas sim a capacidade que cada um possui em explorar os erros cometidos pelo adversário a seu favor. A forma como o jogador corrige suas jogadas com base nos seus próprios erros e a rapidez com que ele consegue fazê-lo também evoca essa experiência estética de desafio.

Em todos os jogos, foi percebido que muitos dos tipos de Erro Humano de Baber \& Stanton (1994) e Kirwan (1996) acontecem em simultaneidade, ou em sequência aos tipos de erro de Reason (1990), e isso pode ser explicado devido às definições desses tipos de acordo com as visões de cada autor. No caso de Erros no Nível das Perícias, pela sua definição, são erros que envolvem deslizes em atividades ditas como automáticas, como na situação do jogo Dark Souls 2 - Scholar of the First Sin, onde o jogador executou uma ação no tempo errado aos 10 minutos e 36 segundos do vídeo; esse tipo de situação também pode ser classificado como um Erro de Tempo, de acordo com Baber \& Stanton (1994) e Kirwan (1996). Apesar da simultaneidade, isso não altera o processo de criação dos princípios, visto que o objetivo da análise era a de identificação dos erros.

Outro dado interessante que foi observado durante a análise dos vídeos foi a melhora da performance do usuário à medida que ele tentava cumprir seu objetivo novamente. Conclui-se que só pôde haver melhora no desempenho do jogador por causa do Erro Humano. A sensação de frustração (devido ao erro) e o desejo de superar o desafio acabam se tornando uma motivação paradoxal. Entende-se que essa relação foi o ponto de partida para o desenvolvimento dos princípios. Para auxiliar nessa tarefa, o quadro 11 apresenta os dados coletados de forma resumida.

Quadro 11 Resumo dos dados coletados.

\begin{tabular}{llll}
\hline Nome do Jogo & Dark Souls 2 & Darkest Dungeon & Hearthstone \\
\hline Objetivo do Jogador & $\begin{array}{l}\text { Derrotar o inimigo } \\
\text { denominado “The Pursuer" }\end{array}$ & $\begin{array}{l}\text { Concluir as missões apresentadas } \\
\text { pelainterface do jogo }\end{array}$ & $\begin{array}{l}\text { Vencer adversários no } \\
\text { modo “Play" }\end{array}$ \\
\hline Estéticas Identificadas & Desafio & Desafio & Desafio \\
(Hunicke et al., 2004) & Fantasia & Fantasia & Fantasia \\
& Sociedade & Narrativa & \\
\hline Sujeição & Sujeição & Conhecimento (5) \\
(Rasmussen, 1987) & Perícias (5) & Regras (3) & \\
\hline Erros identificados & Tempo (12) & Conhecimento (3) & Leitura (2) \\
(Baber \& Stanton, 1996; & Qualidade (3) & Planejamento (4) & Planejamento (5) \\
Kirwan, 1998) & Leitura (5) & Seleção (4) & Seleção (3) \\
& Planejamento (3) & informação (5) & \\
\hline
\end{tabular}




\section{Triangulação dos dados - Erros Identificados e a Teoria de Fluxo Expandida}

O que foi observado no jogo Darkest Dungeon, a falta de uma descrição clara de uma de suas mecânicas básicas - fugir da luta levou o jogador a um erro de transmissão de informação. Nesse jogo, é estabelecido que fugir faz parte da experiência estética, uma vez que o jogador é induzido ao erro por falta de clareza no ícone da interface gráfica, o que leva o jogador a sair do fluxo. Já no jogo Dark Souls 2 -Scholar of the First Sin o que se observou é que os erros de qualidade, de tempo e de leitura estão relacionados com a dificuldade do jogo que, por sua vez, se relaciona com a estética de desafio. O mesmo pode ser dito sobre o jogo Hearthstone - Heroes of Warcraft, onde a estética do desafio é presenciada na dinâmica dos duelos entre os jogadores.

Logo, foi possível concluir que existe uma relação entre os erros identificados e a experiência estética. Os erros que estão relacionados à estética do jogo fazem com que o jogador entre em fluxo. Quando o erro não tem relação com a experiência estética, o jogador percebe o jogo como "injusto", ou "muito difícil", assim saindo do fluxo. Com essas observações, o gráfico da teoria do fluxo expandido (Zaffari e Battaiola, 2014) pode ser complementado conforme a figura 5.

Com os dados da análise, também foi possível fazer a triangulação entre as classificações de erros de Baber \& Stanton (1996) e Kirwan (1998), a de Reason (1990) com a classificação de mecânicas de Goodman (2010) e as estéticas de Kirwan et al. (2008). Os níveis do comportamento de Rasmussen (1989) - Perícia, Regras, Conhecimento - estão associados, segundo Goodman (2010), com os três tipos de mecânicas que se encontram nos jogos digitais (quadro 12).

As informações nos quadros 11 e 13 possibilitam triangular as teorias das habilidades do jogador de Järvinen (2008), do modelo MDA, do modelo SRK e as classificações de Erro Humano de Baber \& Stanton (1996) e Kirwan (1998). O quadro 13 apresenta a associação de teorias. 
Figura 5 Teoria do fluxo expandido [OMITIDO PARA REVISÃO CEGA] relacionado aos erros

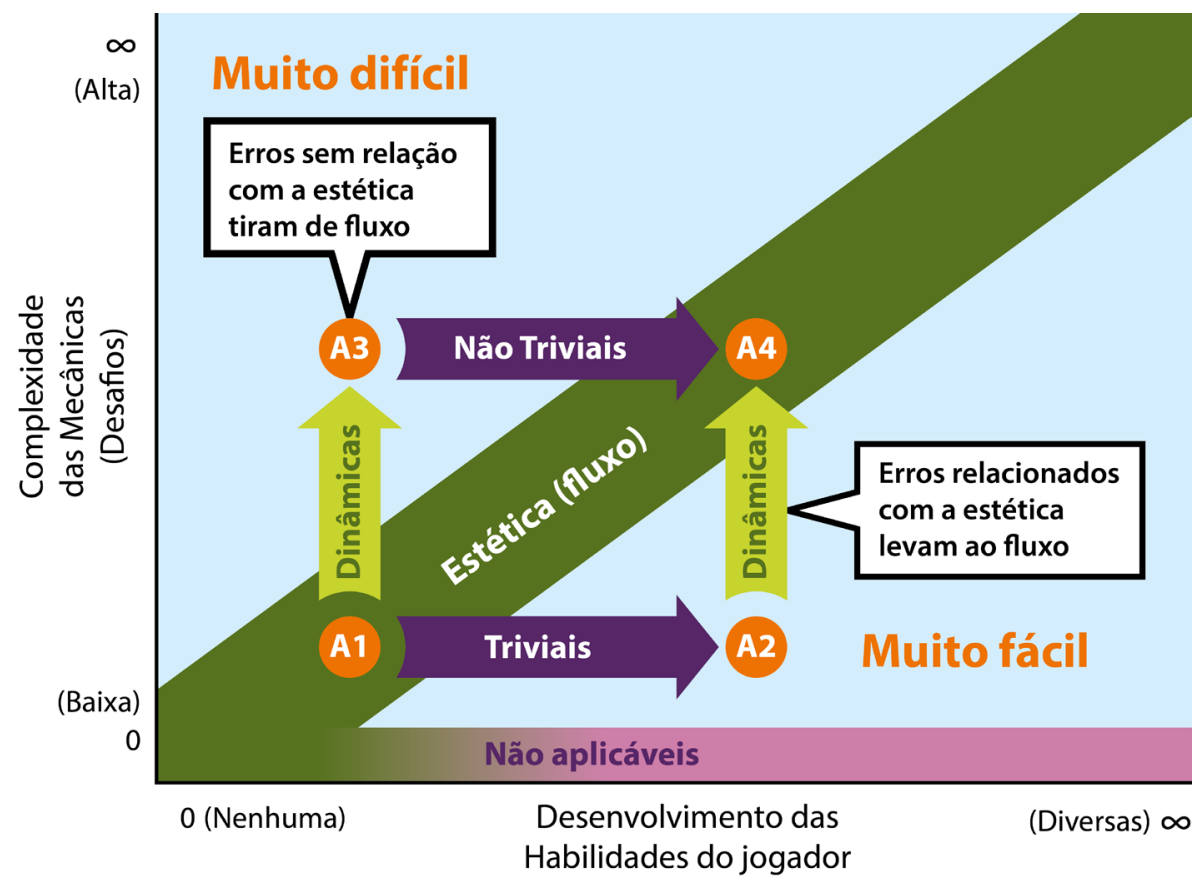

Cada par de cores nas legendas representam as teorias de cada autor:

Teoria do fluxo

Csikszentmihalyi (1990)

Modelo MDA

Hunicke et al. (2004)

Habilidades

Järvinen (2008)

Quadro 12 Associação entre o modelo SRK de Rasmussen (1989) e as classes de mecânicas, adaptada de Goodman (2010).

\begin{tabular}{|c|c|}
\hline \multicolumn{2}{|c|}{ Comportamento no nível das perícias } \\
\hline Mecânicas básicas & Mecânicas primárias \\
\hline \multicolumn{2}{|c|}{ Comportamento no nível das regras } \\
\hline Mecânicas primárias & Mecânicas secundárias \\
\hline \multicolumn{2}{|c|}{ Comportamento no nível do conhecimento } \\
\hline & \\
\hline
\end{tabular}


Quadro 13 Triangulação entre teorias: modelo SRK de Rasmussen (1989), modelo MDA de Hunicke et al (2008), classificação de Baber \& Stanton (1996 e Kirwan (1998) e as classes de mecânicas de Goodman (2010).

\begin{tabular}{llll}
\hline & Nível das perícias & Nível das regras & Nível do conhecimento \\
\hline $\begin{array}{l}\text { Descrição do } \\
\text { comportamento }\end{array}$ & Ações automáticas & $\begin{array}{l}\text { Ações condicionadas } \\
\text { por regras }\end{array}$ & $\begin{array}{l}\text { Ações com base em } \\
\text { experiência } \\
\text { passada }\end{array}$ \\
\hline Tipo de Habilidade & Triviais & Não-triviais & Não-aplicáveis \\
\hline Mecânicas & Básicas & Primárias & Secundária \\
\hline Primárias & Secundárias & Planejamento \\
& Omissão & Seleção & Transmissão da informação \\
& Qualidade & Sequência & Leitura \\
\hline Estéticas & Desafio & Descoberta \\
& Sujeição & Soxprasia & Narrativa \\
& & & Sensação \\
\hline
\end{tabular}

\section{Princípios para o design de jogos digitais}

Após a inspeção preventiva de erro nas sessões de jogos gravadas e o estabelecimento de relações entre os tipos de Erro Humano e as estéticas do MDA de jogos digitais, como representados pelo quadro 13, do item anterior, foram observados os princípios de Erro Humano organizados no quadro 7.

Para a triangulação entre as teorias de jogos digitais e as recomendações para o design e a IHC, houve a preocupação em analisar dois quesitos para a construção dos princípios para jogos digitais:

1. A forma como cada um é redigido: Tempos verbais que são utilizados para a redação de cada princípio; quantidade de detalhes para a explicar como aplicar o princípio no design do jogo.

2. A pertinência para o design de jogos: (1) Avaliar a possibilidade de o princípio de Erro Humano interferir com as experiências estéticas. Por exemplo, Princípios cujo objetivo sejam corrigir erros de qualidade da ação e erros de tempo podem interferir na experiência estética de desafio e de sujeição; (2) Caso o princípio de Erro Humano não interfira com a experiência estética, pode-se considerar esse princípio como aplicável ao design de jogos digitais.

Considerando esses critérios, portanto, são apresentados 11 princípios para o design de jogos digitais. Cada princípio é apresentado em duas partes: uma frase que resume de forma simples o que o princípio tenta recomendar ao design do projeto; uma descrição com mais detalhes de o que pode ser feito para se aplicar o efeito desejado do princípio em si. 
Os princípios são agrupados em 4 categorias: Forçar, Prevenir, Punir e Recuperar. Elas elucidam de forma resumida o que cada um pretende causar como efeito no design de um jogo. Os princípios da categoria Forçar (quadro 14) recomendam que o designer pense em mecânicas que forcem situações durante o jogo. Essas situações devem forçar o jogador a cometer erros no nível das perícias (erros de qualidade da ação e de tempo) em um jogo na qual a estética de desafio seja a principal.

Quadro 14 Princípios para Forçar.

\begin{tabular}{l}
\hline Forçar \\
\hline Apresente novos desafios no decorrer do jogo. Erros no nível das regras são comuns de \\
acontecer durante o início da sessão, onde as habilidades do jogador ainda são não-triviais. A \\
medida que o jogador aprende as regras do jogo, ele não se sente mais desafiado. Force erros \\
no nível das regras ao introduzir uma nova mecânica primária que o jogador não conheça. \\
\hline Aumente a complexidade do desafio à medida que o jogador vence. Se a intenção do \\
designer for de não incluir novas mecânicas primárias no decorrer da partida, então ele pode \\
optar por aumentar a complexidade do desafio aumentando a quantidade de elementos \\
que o jogador deve lidar. Esse tipo de ajuste fará com que aconteçam mais erros no nível \\
das perícias.
\end{tabular}

Os princípios da categoria Prevenir (quadro 15) são relativas à transmissão da informação do jogo para o jogador. Esses princípios descrevem a preocupação que o designer deve ter em trazer a informação para o jogador a fim de que os erros cometidos pelo jogador sejam percebidos inteiramente como culpa dele, prevenindo situações onde o jogador erre por falta de informação.

Quadro 15 Princípios para Prevenir.

\begin{tabular}{l}
\hline Prevenir \\
\hline Forneça feedback das ações do jogador no jogo a todo momento de todas as maneiras \\
possíveis. Utilize o ambiente do jogo, os efeitos sonoros, a música, ou qualquer outro recurso \\
sensorial em combinação para fornecer ao usuário informações sobre as ações que ele exerce \\
sobre o mundo virtual. Faça com que ele entenda o seu efeito nos elementos do jogo. \\
\hline Informe o estado do jogo de forma clara. O jogador deve estar sempre informado do \\
estado do jogo em todos os momentos durante a sessão. Erros na coleta e transmissão de \\
informação devem ser corrigidos pelo designer. \\
\hline Na interface, deixe clara todas as opções disponíveis para o jogador. Na linha de raciocínio \\
do princípio sobre informação dos estados, é importante criar um mostrador na interface \\
que, de forma resumida, deixe claro o que o jogador pode ou não fazer. Se existe uma \\
mecânica primária, (como fugir da luta, por exemplo) mostre-a. Evite erros de transmissão \\
da informação por falta de comunicação entre a interface e o jogador. \\
\hline O erro precisa ser mostrado na interface de forma clara para o jogador. Quando o jogador \\
comete erros no nível das regras, como erros de qualidade da ação, seleção, sequência, ou \\
tempo, o sistema deve oferecer um feedback claro e sem ambiguidade. Utilize os recursos da \\
interface gráfica, como sons, números, animações para \\
transmitir esse tipo de informação
\end{tabular}


Os princípios da categoria Punir (quadro 16) recomendam ao designer de jogos que sejam criadas mecânicas que façam o jogador se sentir responsável pela sua falha. Quando o usuário erra e não existe nenhum impacto na experiência, a atividade deixa de ser divertida.

Quadro 16 Princípios para Punir.

\begin{tabular}{l}
\hline Punir \\
\hline Faça com que erros consecutivos causem perdas permanentes. Se ojogador falhar em \\
alcançaro seu objetivo, faça com que o jogador possa recuperar o que perdeu no momento \\
do erro (unidades, pontos de vida, dinheiro). Se o jogador não conseguir se recuperar, o \\
designer pode fazer com que essa perda seja permanente, isso faz com que o jogador fique \\
em um estado de tensão que facilita a entrada no fluxo. \\
\hline Faça com que o jogador seja punido por seus erros. Quando o jogador erra e seu erro não \\
tem impacto no estado do jogo o desafio não é percebido. Quando isso acontece, o jogador \\
sai de fluxo e perde o interesse na atividade. \\
\hline O erro deve ter um impacto no jogador que tenha relação com a experiência do jogo. Se o \\
objetivo do designer, com o jogo, é desafiar um aspecto específico do comportamento do \\
jogador, os erros cometidos devem ser severamente punitivos, por exemplo, os designers \\
de Dark Souls 2 punem o jogador no nível das perícias projetando inimigos que derrotam o \\
avatar digital em poucos ataques.
\end{tabular}

Os princípios da categoria Recuperar (quadro 6.10) recomendam que haja possibilidade de o jogador tentar vencer um desafio mais de uma vez, ou então desistir completamente. O propósito é dar controle ao jogador sobre as circunstâncias do desafio que ele encara.

Quadro 17 Princípios para Recuperar.

\begin{tabular}{l}
\hline Recuperar \\
\hline Permita que o jogador se recupere do erro. Crie mecânicas primárias ou secundárias que \\
permitam que o jogador tente vencer o desafio de novo, depois de falhar. Mecânicas como \\
"salvar jogo", "vidas extra", "pontos de saúde" e "pontos de controle" são algumas das \\
opções possíveis de se fornecer uma chance do jogador se recuperar. \\
\hline Permita que o jogador possa desistir. Quando as habilidades do jogador ainda são não- \\
triviais, existirá o momento onde ele não conseguirá superar o desafio. Cabe a ele correr o \\
risco de avançar e falhar, ou de fugir e melhorar suas habilidades. O designer deve permitir \\
que o jogador fuja para poder evitar erros de planejamento. \\
\hline
\end{tabular}

Com os princípios de design de jogos colocados em suas respectivas categorias e explicado o propósito de cada uma delas, cabe agora uma análise geral do resultado da pesquisa e considerações finais em relação ao projeto como um todo, o que é tema do próximo item. 


\section{Conclusões e Considerações Finais}

O projeto de pesquisa apresentado buscou como objetivo geral fazer a incorporação dos princípios de Erro Humano ao design de jogos digitais. O meio que se utilizou para estabelecer essa relação foram os princípios mencionados anteriormente. Assim, o que se conclui dessa pesquisa é que os princípios de IHC sobre Erro Humano encorajam o designer de interface a projetar um sistema onde, mesmo que não desejado, o erro tenha um impacto mínimo na performance da operação. Isso é esperado, considerando o contexto onde os primeiros estudos desse assunto surgiram (usinas nucleares e bases militares). É evidente que o Erro Humano, sob essa ótica, é indesejável pelo seu impacto direto na vida do ser humano, onde um erro pode causar uma série de fatalidades.

Nos jogos digitais, como não existe um perigo real para o ser humano, o erro é observado com menor importância, entretanto ele ainda se torna indesejado e constante na experiência desse tipo de produto. Com base no que foi analisado, pode-se chegar à conclusão que, paradoxalmente, o Erro Humano faz parte da diversão do jogo. Sem a possibilidade de o jogador errar, o propósito da atividade se perde.

Sobre o método de coleta de dados e análise, cumpre ressaltar que a inspeção foi realizada a partir de um único jogador, o que pode acarretar novos resultados se a inspeção for aplicada com mais participantes, assim, é possível que os princípios passem por modificações.

Analisando outras bibliografias sobre design de jogos, como Adams (2013) e Fullerton et al. (2004), é possível perceber que os princípios descobertos têm paralelos com o que já foi estabelecido. $\mathrm{O}$ que é interessante sobre esses autores é que todos comentam como a derrota (nos jogos) é algo integral à experiência, porém nenhum deles faz referência aos princípios de Erro Humano. Ainda, com base na bibliografia revisada, percebe-se que a pesquisa apresentada neste projeto tem pouca semelhança com outras publicações. Um trabalho que se aproxima do tema estudado é o estudo de Juul (2014) que pesquisa sobre a satisfação de jogadores ao interagirem com jogos muito fáceis/ difíceis. Os resultados da pesquisa desse autor constatam que os usuários preferem que o jogo seja difícil e que a culpa da sua derrota seja percebida como responsabilidade dele, e não do sistema. Os princípios descobertos se aproximam dessa conclusão de Juul (2014). É importante ressaltar que o gráfico da teoria de fluxo expandido, as relações estabelecidas pela triangulação de teorias e os princípios são inéditos.

O que resta agora, depois de concluída a pesquisa, é ampliar a inspeção, a fim de validar os resultados encontrados, além de testar o uso dos princípios no desenvolvimento de um jogo digital. Visto que a análise foi feita com jogos de diferentes níveis de orçamento e tamanho de equipe, acredita-se que a aplicação dos princípios seja ampla o suficiente para que todos os designers de jogos possam utilizálos. Dessa aplicação, será possível testar a qualidade destes princípios e possivelmente melhorá-los em um trabalho futuro. 


\section{Agradecimento}

Os autores desejam agradecer as professoras Drª. Marli Teresinha Everling e Drạ. Stephania Padovani pelas suas contribuições ao resultado da pesquisa.

\section{Referências}

ADAMS, Ernest. Fundamentals of game design. Pearson Education, 2013.

BABER, Christopher; STANTON, Neville A. Human error identification techniques applied to public technology: predictions compared with observed use. Applied Ergonomics, v. 27, n. 2, p. 119-131, 1996.

CSIKSZENTMIHALYI. Mihaly. Flow: the psychology of optimal experience. USA: Harper Perennial Modern Classics edition, 1990.

DEKKER, Sidney. The re-invention of human error. Human factors and aerospace safety, v. 1, n. 3, p. 247-265, 2001.

FULLERTON, Tracy; SWAIN, Chris; HOFFMAN, Steven. Game design workshop: Designing, prototyping, \& playtesting games. CRC Press, 2004.

HUNICKE, Robin; LEBLANC, Marc; ZUBEK, Robert. MDA: A formal approach to game design and game research. In: Proceedings of the AAAI Workshop on Challenges in Game AI. 2004. p. 04-04.

JÄRVINEN, Aki. Games without frontiers: Theories and methods for game studies and design. 2008.

JUUL, Jesper. The art of failure: An essay on the pain of playing video games. Mit Press, 2013.

KIRWAN, Barry. Human error identification in human reliability assessment. Part 1: Overview of approaches. Applied ergonomics, v. 23, n. 5, p. 299-318, 1998.

KIRWAN, Barry. Human error identification techniques for risk assessment of high risk systems-Part 2: towards a framework approach. Applied ergonomics, v. 29, n. 5, p. 299-318, 1998.

NORMAN, Donald A. Design rules based on analyses of human error. Communications of the ACM, v. 26, n. 4, p. 254-258, 1983.

RASMUSSEN, Jens. Skills, rules, and knowledge; signals, signs, and symbols, and other distinctions in human performance models. Systems, Man and Cybernetics, IEEE Transactions on, n. 3, p. 257-266, 1983.

REASON, James. Human error. Cambridge university press, 1990.

WOODS, David D. et al. Behind human error: Cognitive systems, computers and hindsight. DAYTON UNIV RESEARCH INST (URDI) OH, 1994.

ZAFFARI, Guilherme; BATTAIOLA, André Luiz; "MAPEAMENTO DO MDA E HABILIDADES DO JOGADOR NO GRÁFICO DA TEORIA DO FLUXO”, p. 362-373. In: Anais do $11^{\circ}$ Congresso Brasileiro de Pesquisa e Desenvolvimento em Design [= Blucher Design Proceedings, v. 1, n. 4]. São Paulo: Blucher, 2014. ISSN 2318-6968, DOI 10.5151/designpro-ped-00422 


\section{Apêndice}

Para ter acesso aos vídeos gravados durante a pesquisa, utilize o link abaixo para fazer o download dos arquivos respectivos: https:// drive.google.com/folderview?id=oB8dZ-oOxm3ZyQkxpNXBDUU5CO Gs\&usp=sharing

\section{Apêndice A - Gravação de jogo digital Dark Souls 2: Scholar of the First Sin}

Título: Dark Souls 2 - Scholar of the First Sin

Ano de lançamento: 2015

Plataforma em que foi utilizado: Windows PC

Desenvolvedora: From Software

Distribuidora: Bandai Namco da América

Duração da gravação: $31 \mathrm{~m} 25 \mathrm{~s}$

Formato da mídia gravada: Digital (MP4)

\section{Apêndice B - Gravação de jogo digital Darkest Dungeon}

Título: Darkest Dungeon

Ano de lançamento: 2014

Plataforma em que foi utilizado: Windows PC

Desenvolvedora: Red Hook

Distribuidora: Não possui (distribuído independentemente)

Duração da gravação: 34mo1s

Formato da mídia gravada: Digital (MP4)

\section{Apêndice C - Gravação de jogo digital Hearthstone: Heroes of Warcraft}

Título: Hearthstone: Heroes of Warcraft

Ano de lançamento: 2014

Plataforma em que foi utilizado: Windows PC

Desenvolvedora: Blizzard Entertainment

Distribuidora: Blizzard Entertainment

Duração da gravação: 34m21s

Formato da mídia gravada: Digital (MP4) 


\title{
Sobre os autores
}

\section{Guilherme Zaffari}

Mestre, bacharel em design gráfico pelo Centro Universitário Ritter dos Reis (2009), pós-Graduado em desenvolvimentode jogos digitais pela PUC-RS (2001), mestre em design de informação pela UFPR(2015). Área de interesse principal: design de jogos digitais. Área de interesse correlatas: experiência do usuário e design de interação. <guizaffari@gmail.com>

\author{
André Luiz Battaiola \\ Doutor, bacharel em física (1980), mestre em engenharia elétrica \\ (1986) e doutor em engenharia elétrica pela USP (1991), pós- \\ doutorado em visualização científica no Space Science and \\ Engineering Center (SSEC) da Universidade de Wisconsin, Wi, \\ EUA (1993). Área de interesse principal: jogos educacionais. Área \\ de interesse correlatas: animação, narrativas e design de jogos \\ de computador. \\ <ufpr.design.profe.albattaiola@gmail.com>
}

Artigo recebido em 20 jul. 2015, aprovado em 09 out. 2015. 